\title{
SIGNOS DA MORTE COMO EXPRESSÂO DO EROTISMO EM CONTOS DE AUTORIA FEMININA ${ }^{1,2}$
}

\author{
SIGNS OF DEATH AS AN EXPRESSION OF EROTICISM IN \\ SHORTS STORIES OF FEMALE AUTHORSHIP
}

Luciana Borges ${ }^{3}$

\begin{abstract}
RESUMO: O presente trabalho analisa a antologia de contos Intimidades: dez contos eróticos de escritoras brasileiras e portuguesas, organizada por Luisa Coelho (2005). Composta de contos exclusivamente de lavra feminina, apresenta narrativas de temática sexual em cruzamento com questões de investiduras de gênero (gender) de modo a constituir o erotismo como uma experiência interior, subjetiva, e não apenas física, para as personagens retratadas. Transgressões, recuos estratégicos, conflitos, são mostrados de mistura com a díade continuidade e descontinuidade, reenviando, assim a um motto central da vida erótica em perspectiva batailliana: a proximidade intrínseca com a morte. Nos contos, portanto, a convivência de Eros e Thanatos será tomada como norteadora das estratégias de representação do sexo e do desejo nas fissuras da existência.
\end{abstract}

Palavras-chave: Morte. Erotismo. Autoria feminina. Antologias.

ABSTRACT: The present study analyses the anthology of short stories entitled Intimidades: dez contos eróticos de escritoras brasileiras e portuguesas, organized by Luisa Coelho (2005). Composed of tales exclusively from female mining, it presents narratives of sexual theme in intersection with issues of gender endowments in order to constitute eroticism as an interior, subjective experience, not only physical, for the depicted characters. Transgressions, strategic setbacks, conflicts are shown mixed with the dyad continuity and discontinuity, thus resubmitting to a central motto of the erotic life in a bataillian perspective: the intrinsic proximity with death. In the tales, however, the coexistence of Eros and Thanatos will be taken as a north of sex and desire representation strategies in the chinks of existence.

Keywords: Death. Eroticism. Female authorship. Anthologies.

\footnotetext{
${ }^{1}$ Artigo recebido em 15 de agosto de 2019 e aceito para publicação em 27 de novembro de 2019 ${ }^{2}$ Este texto é parte dos resultados de um projeto de pesquisa sobre antologias de contos eróticos de autoria feminina, vinculado a Pós-Doutorado na Universidade Federal de Santa Catarina, e financiado pela Fundação de Amparo à Pesquisa do Estado de Goiás - FAPEG.

${ }^{3}$ Doutora em Letras - Estudos Literários pela Universidade Federal de Goiás, com Pós-Doutorado na Universidade Federal de Santa Catarina e Professora na UFG - Regional Catalão. Pesquisa Literatura de Autoria Feminina com ênfase em estudos de gênero, erotismo e pornografia. Membro do grupo Dialogus (CNPq), do GT Anpoll - A mulher na literatura e do Coletivo Literário Mulherio das Letras. E-mail: borgeslucianab@gmail.com. ORCID: https://orcid.org/0000-00030018-2425. ResearcherID: AAD-3752-2019..$\quad$ Scholar Google: https://scholar.google.com.br/citations?hl=pt-BR\&user=oFvfpBsAAAAJ.
} 


\section{0 campo teórico do erotismo e a autoria feminina da ficçăo erótica: lacunas e ressignificaçôes}

“O erotismo é possível dizer que ele é a aprovação da vida até na morte": É a partir da citada e recitada afirmação de Georges Bataille (2004, p. 20) em seu fundador e já clássico ensaio sobre o erotismo que estabeleço o ponto de partida para as reflexões que o presente estudo apresenta sobre a relação entre escrita do erótico por mulheres e a ocorrência dos signos de morte em narrativas de temática sexual ou amorosamente erotizadas no conjuntos de textos ficcionais de autoria feminina aos quais tenho me dedicado nos últimos anos ${ }^{4}$. Uma segunda preocupação desse texto é pontuar como os estudos do erotismo tem se colocado em relação às questões da autoria feminina, tanto de textos ficcionais quanto de textos teóricos, em termos das hierarquias de gênero vigentes na sociedade ocidental, as quais resultam na invisibilidade e desvalorização da produção intelectual e artística de mulheres ao longo do tempo.

A representação da relação entre erotismo e morte em alguns textos selecionados constitui então o foco do presente texto, portanto, conforme anunciado no resumo desta proposição, analiso a antologia de contos Intimidades: dez contos eróticos de escritoras brasileiras $e$ portuguesas, organizada por Luisa Coelho (2005). Composta de contos exclusivamente de lavra feminina, apresenta narrativas de temática sexual em cruzamento com questões de investidura de gênero (gender). As dez escritoras abordam os temas sexuais e afetivos de modo que executam, por meio da linguagem, outra máxima de Bataille (2004), segundo a qual, o erotismo é aquilo "que coloca o ser em questão". Constituído como uma experiência interior, subjetiva, e não apenas física, como poderia sugerir o intercurso sexual, a partir da confluência dos corpos.

Transgressões, recuos estratégicos, conflitos existenciais e quebras de limite da segurança em termos da manutenção da vida são mostradas de mistura com a díade continuidade e descontinuidade, reenviando, assim a um segundo motto central da vida erótica em perspectiva batailliana: a sua proximidade intrínseca com a morte. Nos contos, como pretende-se mostrar,

\footnotetext{
${ }^{4}$ Um dos estudos anteriores encontra-se no livro O erotismo como ruptura na ficção brasileira de autoria feminina (Editora Mulheres, 2013), no qual discuto aspectos da obra de Clarice Lispector, Hilda Hilst e Fernanda Young, em torno dos projetos literários que as referidas autoras executaram a partir de certa interpelação pelos temas sexuais na ficção.
} 
a convivência de Eros e Thanatos será tomada como norteadora das estratégias de representação do sexo e do desejo nas narrativas.

Antes de nos debruçar especificamente sobre as narrativas e o modus operandi em que acionam os signos de morte, é necessário pensar uma outra relação, anterior: a relação entre erotismo, questões de gênero e autoria feminina, reflexões sem as quais corremos o risco de tratar o nosso objeto de forma distorcida ou ineficiente. A supracitada relação leva em conta o modo como as estruturas patriarcais e androcêntricas constituem a sociedade ocidental, de modo que não apenas as relações entre indivíduos, mas toda a composição da sociedade se torna genderificada, ou seja, as investiduras do gênero como sendo a categoria mental que norteia as posições, valores, escolhas e papéis de homens e mulheres na coletividade.

A produção literária, imersa nesse contexto cultural e simbólico, será afetada por esses modos de representação e o campo do erotismo não estará isento, mesmo porque, no caso dessa ficção, o entrelaçamento com as questões da sexualidade, da repressão e dos modos como a sociedade ocidental configurou sua relação com o desejo serão determinantes para os universos narrativos criados e para a composição de personagens imersas nas tramas dos usos ou desusos do corpo e dos prazeres. Os estudos de Michel Foucault, apresentados no primeiro volume de História da sexualidade (2001) não deixam dúvidas sobre como a relação entre sexualidade, discurso e poder são constitutivas dos modos como os temas sexuais são suprimidos ou supervalorizados dependendo do contexto de legitimidade ou deslegitimidade em que se encontrem.

Isto posto, a primeira consideração diz respeito ao apagamento das mulheres autoras do conjunto das narrativas eróticas, de modo que as referências de erotismo e sua representação na literatura não raro se concentram em nomes de autores masculinos, de modo que as mulheres escritoras se encontram em menor número, carecendo sempre do acionamento de estratégias de revisão e resgate crítico que reenvie suas obras para uma posição visível no elenco de autores que tenham se dedicado aos temas do erotismo.

É o caso, por exemplo, no contexto da história literária do Brasil, da escritora Cassandra Rios (1932-2002), cuja obra foi rotulada de obscena e pornográfica por inserir nas suas tramas ficcionais, além de uma representação pouco convencional das relações afetivas, temas como a 
homossexualidade, a travestilidade e a transexualidade. 0 resultado foi ter visto sua obra relegada pela crítica ao âmbito de paraliteratura, considerada sem mérito estético suficiente para ser objeto de estudos acadêmicos e inserção da autora no rol das representatividades nacionais da literatura, como aconteceu, resguardadas as diferenças, com outras escritoras suas contemporâneas, como Clarice Lispector e Lygia Fagundes Telles, por exemplo.

A segunda consideração se relaciona ao fato de que, na ficção e nas representações que possam se apresentar em termos de uma autoria masculina dos universos narrativos e seus desdobramentos, a colocação das mulheres como objeto de prazer visual ou textual, a predominância fálica será repercutida na literatura tanto em termos da voz autoral quanto em termos da construção de enredos de temas sexuais nos quais as mulheres são personagens. Não apenas a autoria ficcional se ressentirá dessa condição androcêntrica estrutural, mas pode-se considerar que as próprias elaborações teóricas mais utilizadas para nortear o campo do erotismo expressam perspectiva fálica em relação aos processos sexuais, usos do corpo e dos prazeres.

Georges Bataille (2004), por exemplo, ao argumentar sobre o par continuidade/descontinuidade afirma que a parte feminina, passiva, é sempre a parte dissolvida para a fusão posterior. Ainda que enfatize um suposto motivo ou intuito dessa dissolução prévia feminina (a fusão posterior e a equivalência dessa dissolução), a pressuposição de que a parte feminina, ou como poderíamos deduzir pelo contexto, a mulher, é passiva, reverbera as posições mais comuns a respeito da sexualidade feminina em ambiente heterossexual no Ocidente. A passividade das mulheres é considerada em amplo espectro, desde um culto social ao pudor feminino, supervalorização da virgindade como item de honra e valor para as mulheres, até os processos mais comuns na pornografia que, por excesso, retratam a submissão e passividade feminina de modo extremo. É evidente que o texto de Bataille tenta apresentar esse "ser", ao qual ele se refere, como uma abstração dos sujeitos, a qual englobaria homens e mulheres. No entanto, os mecanismos dessa argumentação reenviam à compreensão desse sujeito como masculino e heterossexual.

A última consideração diz respeito ao apagamento das mulheres em termos das formulações teóricas sobre o erotismo que são utilizadas 
como fontes teóricas ou categorias de análise. Grande parte do referencial teórico circulante é produzido por homens, a exemplo do já citado Bataille. Um caso emblemático desse apagamento é a circulação infinitamente menor ${ }^{5}$ de um ensaio escrito por Lou Andreas-Salomé, O erotismo, em décadas anteriores ao estudo de Bataille que, inclusive, cita-o na lista de referências do livro $O$ erotismo.

O ensaio, inicialmente publicado no ano de 1910 em uma revista de Frankfurt ${ }^{6}$, intenciona uma abordagem do erotismo (ou da Erótica) para além dos aspectos da vida sexual ou dos referentes físicos/ fisiológicos da atividade reprodutiva, ressaltando que, qual seja a tentativa de teorização do assunto, esta resultará em algo sempre parcial. A autora se dedica a explorar os aspectos que ela chama de "espirituais" do erotismo, tendo em vista todo o espectro das relações psíquicas, físicas e sociais complexas que fazem do erotismo algo não autônomo ou em-si, como se poderia supor à época. Investiga também a subjetividade que envolve sua proximidade com o que se convencionou chamar de amor. Para a autora,

o erótico em seu aspecto animal não se restringe apenas a que o animal superior acompanha seu comportamento sexual com o afeto cerebral que excita sua matéria nervosa; também o sexual torna-se sensação, e finalmente romantismo, dando assim seu conteúdo em todas as ramificações, motivos e nuances nos recintos mais individualmente humanos ${ }^{7}$.

Bataille leitor de Lou Salomé? Qualquer semelhança com a argumentação de Bataille sobre a diferenciação entre a atividade sexual humana e animal seria mera coincidência? Na sequência do texto, Lou Salomé elabora, no item intitulado "O processo sexual", a intrínseca relação entre erotismo e morte, em uma formulação não muito extensa, mas muito aproximada das que posteriormente seriam apresentadas por Bataille em seu ensaio:

\footnotetext{
${ }^{5}$ Mesmo a aquisição desse livro no Brasil é complicada: um exemplar da edição em português, em um portal de livros usados como o Estante Virtual custa cerca de duzentos a trezentos reais. ${ }^{6}$ Título original: La erótica. Revista "Die Gesellschaft", ed. por Martin Buber, Frankfurt, 1910.

${ }^{7}$ Lo erótico em su aspecto animal no se restringe únicamente em que el animal superior acompaña su comportamento sexual com el afecto cerebral que pone em excitación su matéria nerviosa; también lo sexual se convierte em la sensación, y finalmente em la romântica, dando así su contenido em todas las ramificaciones, cimas y matices en el recinto de lo más individualmente humano. (Andreas-Salomé, p. 70).
} 
a forma mais primitiva de união entre os seres vivos é a união total do indivíduo [com outro], que é um símbolo do que acontece nos sonhos mais sublimes do espírito em meio à plena alegria do amor. E é por isso que o amor também se sente tão facilmente tensionado por suas ansiedades e suspeitas da morte, que dificilmente podem ser diferenciados um do outro, de algo que parece um sonho primordial: nesse sonho eu mesmo, a pessoa querida, ou o filho de ambos ainda podem ser um, e ao mesmo tempo três nomes para a mesma imortalidade. ${ }^{8}$

As proposições bataillianas posteriores sobre a relação entre continuidade e descontinuidade do ser como itens basilares do erotismo parecem se relacionar profundamente a essas primícias da relação entre a projeção do amor e da ligação afetiva de um ser como o outro como mecanismo de manutenção de uma ideia de imortalidade, ou mesmo de uma crença no adiamento da morte por via da relação erótica e da geração de descendentes mútuos. Ainda que Lou Salomé apareça na lista de referências da obra de Bataille e que seu ensaio anteceda ao dele em cerca de quarenta anos, esta autora, muito citada em termos de seus estudos psicanalíticos, de sua relação com Sigmund Freud, Friedrich Nietzsche e Rainer Maria Rilke ou por seu estilo de vida libertário, não é citada como uma precursora de Bataille e dos estudos sobre o erotismo, pelo menos em termos do que eu tenha pesquisado no contexto brasileiro. Para Fani Hisgail (2017) na obra de Lou Salomé "somente pelo domínio do erótico que a conservação da vida apoiase em Eros, mesmo que em última instância a morte dance a música macabra da finitude e do gozo." Em que pese os contextos diferenciados, a discrepância cronológica e a profunda expansão que Bataille elaboraria na relação entre erotismo, morte e êxtase a pequena circulação do ensaio de Lou Salomé nos diz muito sobre o modo como a produção intelectual e literária de mulheres circula no Ocidente.

De modo semelhante, as considerações de Anaïs Nin (1969 [2005]) sobre as relações entre sexo, erotismo e linguagem poética de certo modo se

\footnotetext{
${ }^{8}$ De tales influencias bien puede derivar, precisamente por ser la más primitiva forma de unión entre seres vivos la total unión los indivíduos, el que sean símbolo de cuanto acontece em los más sublimes sueños del espíritu entre el pleno gozo amoroso. Y por ello también el amor se siente tan facilmente transido por sus ansias y recelo de muerte, que difícilmente pueden diferenciarse entre sí, de algo que se antoja como um sueño primigênio: en el que lo próprio yo, la persona amada, u el hijo de ambos pueden todavia ser uno, y a la par tres nombres para una misma inmortalidad (ANDREAS-SALOMÉ, p. 73-74)
} 
mantém confinadas à sua leitura como autora de textos eróticos e não como uma pensadora da natureza do erótico e de sua materialização em narrativas. As ponderações que ela envia ao Colecionador, por ocasião da escrita de Delta de Vênus são, em seu cerne, teorização sobre o modo como um texto de temática sexual deveria ser escrito para que tocasse de modo mais intenso o psiquismo de leitores e leitoras e reverberam as intercessões entre erotismo dos corpos e dos corações efetuadas posteriormente por Bataille, bem como a relação entre erotismo e êxtase estético pela arte, propostas por Lou Andreas-Salomé. O prefácio em que Anaïs Nin expressa essas importantes reflexões sobre a escrita do texto de temática sexual permanece lido como opiniões partciulares da autora e não como um modo de pensar, estruturada e estrategicamente o campo discursivo do texto erótico, sua retórica e efeitos, seus movimentos de linguagem e seus meandros de sentido.

Assim como modos de pensar o erotismo por mulheres são relegados ao ostracismo, modos de escrever e ficcionalizar o sexo também o foram no Ocidente como um todo e o contexto brasileiro não escapa a esse processo, que tem profundas raízes na cultura de supremacia intelectual e criativa atribuída aos homens. Textos de temática sexual escritos por mulheres usualmente restam diluídos no conjunto de suas obras por diversos motivos, no entanto, o principal motivo segue sendo a natureza das investiduras de gênero que associam a sexualidade feminina ao passivo, ao retroflexo e ao subalterno em relação à sexualidade masculina. A associação com o amor e a afetividade (não raro pela via da maternidade compulsória) também são barreiras históricas para que as mulheres se dediquem a textos de temas eróticos.

Conforme aponta Ria Lemaire (1994) em seu referencial ensaio sobre os modos como a crítica feminista pode reler a história literária em termos de uma reconfiguração da memória da cultura e da literatura, propomos, como o estudo geral das antologias, inscrever a ficção erótica feminina no conjunto de textos que expressam como as políticas do corpo e dos afetos se expressa na literatura brasileira. Não se trata de criar uma linhagem substitutiva ou à parte das inúmeras materializações do "sexo em discurso" como diria Foucault (2001) e das eróticas literárias já existentes, mas a inserção da dessses textos em um conjunto mais amplo, para que sejam visibilizados, lidos e analisados criticamente como merecem ser. 
A existência de antologias (e aqui me refiro às de contos), nesse sentido, é de fundamental importância para a visibilidade desses textos em conjunto, uma vez que, ao reunir textos dispersos em um só volume temático, dão relevo e relevância a essa produção e jogam luz sobre os aspectos da produção feminina. Nesse momento não é relevante pensar em quão problemáticas podem ser as escolhas e organização de antologias, uma vez que as reuniões de textos, não raras vezes, podem também resultar em hierarquias, preferências subjetivas e exclusões.

É mais produtivo pensar que as antologias, ainda que problemáticas em diversos aspectos, para além de expressar em sua publicação um suposto modus operandi de uma escrita de mulheres, também servem à comprovação de algo que, para iniciadas pode parecer evidente, mas que do ponto de vista de uma coletividade acostumada a perceber a sexualidade e a vida sexual efetiva das mulheres como domesticada e silenciada nem sempre é tão óbvio: mulheres escrevem o sexo. Paradoxalmente, mas não surpreendentemente, as próprias antologias podem ser alvo de apagamento, pelo mesmo processo já descrito anteriormente, cabendo ao campo crítico resgatar essa produção e recolha, ainda que sejam todas do nosso tão próximo século XX.

\section{0 lugar mais íntimo é onde o corpo desaparece? Erotismo, desejo e imagens de morte}

No caso da antologia em análise, Intimidades reúne dez contos autoras brasileiras Ana Miranda, Branca Maria de Paula, Guiomar de Grammont, Lygia Fagundes Telles, Nélida Piñon; e portuguesas Maria Teresa Horta, Rita Ferro, Teolinda Gersão, Lídia Jorge, Inês Pedrosa e explicita o proposito de visibilização de narrativas eróticas por mulheres anunciado desde a apresentação elaborada pela organizadora. O título da coletânea remete ao escrutínio daquilo que seria mais íntimo de personagens e autoras, suas "intimidades", e interpela leitores e leitoras a mergulhar nesse universo interdito, como se olhassem pela fenda da fechadura de uma porta cerrada. Pela natureza do presente trabalho, a análise dos signos de morte ficará concentrada em três contos em que, segundo a organizadora Luisa Coelho "a transgressão é efetuada pelo paroxismo da morte ou pelo desejo de aniquilação" (COELHO, 2005, p. 17) ou em que "a morte ou a proximidade da 
sua ameaça encerra o ciclo do desejo, acalma a inquietação que ele provoca e devolve uma outra vida (COELHO, 2005, p. 17).

O conto "Animal", de Ana Miranda, abre a coletânea com uma instigante construção de desejo e fragmentação do corpo em partes passíveis de morrer. "ele me ama como se eu fosse um animal de estimação" (MIRANDA, 2005, p. 33) é a frase de abertura, seguida por uma enumeração desses "modos de amar", de encenar e desejar a morte da amada.

Para ser mais fácil me matar, desenha com uma caneta imaginária as veias do meu pulso, como se planejasse um corte diz, Aqui você morreria em apenas três minutos e toca na veia de meu pescoço, Aqui em três segundos, encosta um revólver imaginário em meu seio e diz, Aqui morte instantânea sem dor nem sofrimento e dispara enquanto faz o som do tiro em minha boca, seu corpo dentro do meu (MIRANDA, 2005, p. 33).

O trecho em destaque materializa a relação entre pulsão de vida e de morte que se conjugam no erotismo, sendo que, conforme observamos anteriormente, os parâmetros para a parte dissolvida se concentram no corpo feminino, como esse território a ser mapeado e, porque não dizer, esquartejado nas estratégias do gozo. Tal morte é encenada em uma política de desejo na qual o corpo feminino se apresenta como algo a ser apropriado em seus mais recônditos pormenores "Eu te amo por dentro, quero ver o teu coração, beijar teus pulmões, arrancar o teu útero" (MIRANDA, 2005, p. 34). A aniquilação ou mesmo metafórica deglutição do corpo são o modo de, por fim, ainda que de maneira talvez assustadora, inscrever o desejo e o prazer no campo simbólico da continuidade: "teu corpo é a minha casa, onde finalmente posso me sentir só" (MIRANDA, 2005, p. 34). Longe do terror que os enunciados possam causar nas leitoras, a dicção da narradora parece indicar que se passa tudo dentro de um jogo, em que os limites são tensionados ao máximo do campo simbólico. Sexo e morte, posse, esquartejamento e aniquilação parecem compor o mesmo quadro de cumplicidade e pertença, executando uma outra lição de Bataille, que nos lembra que o erotismo é sempre o domínio da violência e da violação do ser. No erotismo, o ser é violado para que se estabeleça a continuidade com o outro, sendo a díade autopreservação e entrega estabelecidade sempre no campo paradoxal da atração dos corpos. É assim que o autor, ao abordar o 
relato transe místico de Santa Teresa como um desses episódios em que as fronteiras entre dor e prazer, morte e vida, desespero e regozijo, agonia e êxtase se esvaem, afirma:

Esse desejo de soçobrar, que fustiga intimamente cada ser humano, difere, contudo, do desejo de morrer pelo fato de ele ser ambíguo: é, sem dúvida, o desejo de morrer, mas é, ao mesmo tempo, o desejo de viver, nos limites do possível e do impossível, com intensidade sempre maior. É o desejo de viver deixando de morrer ou de viver, o desejo de um estado extremo, que talvez somente Santa Teresa descreveu de maneira bastante forte com essas palavras: "Morro de não morrer" Mas a morte de não morrer não é precisamente a morte, é o estado extremo de vida; é a morte que experimento vivendo, continuando a viver. Santa Teresa soçobrou, mas não morreu realmente do desejo que teve de realmente soçobrar. Ela perdeu o pé, ela só fez viver mais violentamente, tão violentamente que ela pode se dizer no limite de morrer, mas de uma morte que, exasperando-a, não interrompia a vida" (BATAILLE, 2004, p. 376-377).

Neste trecho, Bataille descreve o que chama, em outros pontos do texto, de êxtase da morte, esse limbo no qual o corpo experimenta tensionamentos extremos de prazer que se assemelham à sua aniquilação corporal e psíquica. O êxtase da morte, por seu turno, resulta em radicalização da vida uma vez, que, ao divisar essa proximidade com o fim que, de fato, não chega, o que resulta é a experimentação do estar vivo. Esse perder o pé, esse saber-se afogando resta no limite das experiencias interiores propiciadas pelo corpo e pelos sentidos.

A respeito dos modos de consecução do prazer, Judith Butler (2003, p. 108) observa que, às vezes, este exige a "participação imaginária" de partes do corpo, apêndices ou orifícios corporais que podem de fato não pertencer à pessoa. Ocasionalmente é necessário que se imagine um conjunto de atributos corporais materialmente inexistentes. Isto porque, para a mesma autora,

a natureza fantasística do desejo não revela o corpo como sua base ou sua causa, mas como sua ocasião e seu objeto. A estratégia do desejo é em parte a própria transfiguração do corpo desejante. Aliás, para desejar, talvez seja necessário acreditar em um ego corporal alterado, o qual, no interior das regras de gênero do 
imaginário, corresponda às exigências de um corpo capaz de desejo. Essa condição imaginária do desejo sempre excede o corpo físico pelo qual ou no qual ela atua (BUTLER, 2003, p. 108).

No caso do conto, tal natureza fantasística se manifesta na projeção de sua anatomia e fisiologia, elementos protegidos pela pele, que deve ser, então, imaginariamente rasgada para revelar esses itens da posse. Veias, sangue, órgão vitais, vísceras aparecem de mistura com a transformação até mesmo bizarra desse corpo esquartejado em uma casa, ilusão de continuidade a partir do paradoxo da aniquilação e dissolução total do outro no eu. As imagens nada amenas que esse conto evoca produzem, justamente por meio do excesso, o descortinamento dos mecanismos do desejo e da fusão erótica, frequentemente estabelecido de modo apenas metafórico entre os amantes, nas analogias sobre "tornar-se uma só carne", por exemplo, muito frequentes no imaginário cristão do vínculo amoroso.

O segundo conto a compor as reflexões desse artigo, "Sudário", de Guiomar Grammont, apresenta-se como o enredo que eleva ao paroxismo a imagem de gozo da morte, ao construir um protagonista que, literalmente, imprime seu corpo desejante em uma "tela" em momento de gozo e morte literal. Orbitando o desejo pelo corpo de Maria, jovem serviçal da casa, o protagonista lida com a antessala da morte, selada por uma doença terminal que definha seu corpo, transformando-o em um farrapo humano, mas não mina seu desejo, que permanece ardente nas tramas do ardil que planeja para atingir, pelo menos, algum consolo para a morte. A imagem de Maria com a blusa semi-aberta, semi-fechada por um botão que ele desejaria eliminar, reenvia às considerações de Roland Barthes (1987, p. 15), que se pergunta e pergunta a nós: "o lugar mais erótico de um corpo não é lá onde o vestuário se entreabre?" A vontade cotidiana de desnudar e possuir o corpo de Maria que, no entanto, transita pela casa, arredia e como se nada compreendesse, uma menina que é, vai corroendo o psiquismo do protagonista, de modo que os limites entre viver e morrer passam pelo desejo desse contato, o qual o levará à solução final. Ainda com Barthes, no caso da encenação de um acontecimento-não acontecimento,

não se trata do prazer do strip-tease corporal ou do suspense narrativo. Em ambos os casos, não há rasgão, não há margens; há uma revelação progressiva: toda a excitação se refugia na esperança de ver o sexo (sonho 
de colegial) ou de conhecer o fim da história (satisfação romanesca). (1987, p. 16).

Em um expediente desesperado e às voltas com ideias suicidas para se livrar da dor, o protagonista cobre seu corpo nu com tintas, a própria pele com as cores da vida e da morte, estende um tecido no chão e pede à Maria de caminhe sobre seu corpo para imprimir as tintas à tela:

Ela fez exatamente como Ihe pedi. Caminhou até minha nuca, com lentidão e retornou outra vez até meus pés. Eu morria de prazer. A respiração suspensa. Quando os pés tocaram minhas nádegas pela segunda vez, cheguei ao clímax. Não esperava, aconteceu. [...] Depois de alguns instantes levantei-me. Postei-me, então, diante da tela onde meu corpo se encontrava gravado. Junto ao sexo que, comprimido, parecia maior, meu sêmen se misturava à tinta. Minha paixão doía, sem caber dentro de mim. A tela era o sudário que espelhava meu tormento. Desde que cheguei, eu era um moribundo vivendo um calvário. (GRAMMONT, 2005, p. 53 - grifo meu).

$\mathrm{Na}$ sequência à finalização do quadro, ao mesmo tempo desesperada e criteriosa, o protagonista se dirige ao quarto. A última frase do conto sela o destino já anunciado na escolha do termo sudário: “Abri a gaveta, guardei-o [o botão da blusa de Maria encontrado no chão]. A mão estremeceu ao contato da coronha" (GRAMMONT, 2005, p. 54). O desfecho concluso/ inconcluso nos leva a crer que o último registro do corpo vivo é também o registro do corpo que goza, motivo único para se manter a existência e matéria do corpo erótico. O corpo doente, salvo pela morte, é imortalizado por meio do gozo impresso na tela em que se inscreve. Por outro lado, o botão - antes único empecilho à visão da nudez de Maria - jogado no chão e a cozinha abandonada com as tarefas por fazer pode indicar que Maria também havia de certo modo se entregado a esse jogo perigoso. Como nas considerações de Lou Salomé já citadas, a imortalização via erotismo passa, nesse caso, pela aniquilação do corpo, que se torna apenas seu espectro, mas com o signo de vida - o sêmen - misturado às tintas sombrias, ocas e abismais com as quais o protagonista redesenha sua imagem e, de certa forma, transcende o corpo apodrecido e já morto-em-vida, transformando-o, paradoxalmente, em um corpo vivo-para-a-arte. 
O conto de Inês Pedrosa, "Só sexo" com que finalizamos essa breve exposição, explora os limites da continuidade e da descontinuidade erótica por meio da díade sexo/amor com que a narradora se expressa sobre a relação com um antigo companheiro dos tempos de militância política. 0 contexto já passado e rememorado pela protagonista é o da revolução, tempo no qual as demandas ideológicas parecem corroer a possibilidade de qualquer afeto romantizado entre os/as militantes. A protagonista endereça seu desejo ao antigo parceiro: "Queria ser a mesma, nesse encontro. A mesma, com a luz das rugas que me faltavam no tempo em que nos metíamos no corpo um do outro como se sozinhos fôssemos apenas pedaços de um corpo mutilado" (PEDROSA, 2005, p. 58). A memória da continuidade é tamanha que percebemos aquela "ilusão" da qual nos fala Lou Salomé em seus escritos. Igualmente é por esse motivo que a personagem chora a "saudade do êxtase", a nostalgia da junção cósmica a que a união sexual pode fazer supor. Apenas ao final do conto a intrínseca relação entre erotismo e morte é revelada, como justificativa para um derradeiro encontro:

Preciso dessa vida verdadeira que escondi debaixo da tua pele, antes que o cabelo me caia, antes que comecem os enjoos e as dores, antes que o corpo seja tomado pelo cheiro miserável da doença. Talvez para morrer eu precise do amor e da família. Mas para acabar de viver, só preciso de ti, desta febre azul a que os outros chamam só sexo" (PEDROSA, 2005, p. 66).

O trecho "para acabar de viver" sela o vínculo com o êxtase da morte, uma vez que, chegar à morte seria acabar de viver e não necessariamente se estabelecer como um corpo morto. Como no motto de Bataille (2004), o erotismo está nos liames da existência, como parte de uma intensa experiência interior que coloca o ser em questão, fazendo com que questione todos os parâmetros do que dá sentido à vida. O conto de Inês Pedrosa nos reenvia às formulações de Lou Salomé ao observar que, o que as pessoas chamam de "só sexo", como algo menor e sem total relevância, é, na verdade, o que dá sentido ao ser, uma vez que relaciona os aspectos de sua vida psíquica, física e social de modo indissociável. Temos uma protagonista que expressa suas urgências corporais em termos da consciência de que o resto de vida que ainda guarda em seu corpo depende da atividade sexual com esse parceiro com quem a intensidade da interação física é de vida e morte. 
Por outro lado, poder expressar essas urgências e endereçar seu desejo é parte de um conjunto de possibilidades que apenas se apresentam quando a desconstrução dos estereótipos de gênero sobre a sexualidade e a escrita de mulheres começa a se fazer. Temos tanto uma protagonista que advoga a relevância existencial para o sexo, encarado em nosso ambiente ocidental como contrário e negativo à ideia de envolvimento, tanto uma escritora que escolhe como mecanismo narrativo, a voz dessa protagonista como responsável por sua defesa, como a dizer que na vida e na literatura, expressar o desejo e priorizar o corpo são atributos que independem de gênero. Não se trata do antigo estereótipo sexista segundo o qual as mulheres não conseguiriam seccionar a atividade sexual do vínculo amoroso, mas da compreensão de que o vínculo erótico se estabelece para além dos corpos, independentemente de uma ideia de amor. $O$ vínculo erótico é, no caso do conto, o passaporte para o êxtase final, aquele que, encerrando a vida, paradoxalmente the confere o sentido perdido com a doença e reconcilia a personagem consigo mesma e com a finitude inexorável.

\section{Consideraçôes finais:}

\section{Afirmar a vida até na morte ou os paradoxos do erotismo}

Os três contos abordados mostram a materialização das temáticas sexuais por meio da exploração de um dos motivos mais tradicionais do erotismo, qual seja o seu vínculo com a morte. No entanto, a formulação das narrativas, inclusive com o aproveitamento de um narrador masculino, mostra a versatilidade que a escrita erótica de mulheres pode atingir, contrariando o lugar comum que tradicionalmente destinou o romantismo ou as narrativas amenas à lavra feminina. As narrativas também apresentam em sua composição a complexidade das soluções ficcionais adotas pelos projetos literários a partir do século XX, em relação às quais o conto não estaria imune. As ambiguidades, os desfechos enigmáticos ou inconclusos comparecem como itens da filiação dos mesmos a modos específicos de narrar que privilegiam a ambientação interior, psicológica, a queda pela nuance em detrimento da fabulação externa ultra definida.

Tais aspectos corroboram a afirmação de Luisa Coelho na apresentação da coletânea, segundo a qual "no discurso erótico, a sexualidade é linguagem, não apenas de palavras próprias que a dizem e a fazem, mas também de palavras que atravessam as palavras comuns, de 
utilização diária, para voltar a determiná-las eroticamente" (COELHO, 2005, p. 13). Assim, a erotização da/na morte se faz também pela ressignificação da linguagem tanto verbal (a reversão do enunciado "só sexo", por exemplo, em Inês Pedrosa) quanto não-verbal (a gramática de símbolos que se instaura no corpo-tela em Guiomar Grammont ao tratar a arte como mortalha). Na cartografia escatológica e um tanto patológica dos amantes em Ana Miranda, o corpo, o gozo e a morte se intercambiam na reversão entre pulsão de vida e morte, sentidos periclitantes e entrega total.

É Roland Barthes que nos adverte sobre uma diferença bastante produtiva quando aplicada na interpretação da escrita do erótico ficcional e seus meandros:

\begin{abstract}
Texto de prazer: aquele que contenta, enche, dá euforia; aquele que vem da cultura, não rompe com ela, está ligado a uma prática confortável da leitura. Texto de fruição: aquele que põe em estado de perda, aquele que desconforta (talvez até um certo enfado), faz vacilar as bases históricas, culturais, psicológicas, do leitor, a consistência de seus gostos, de seus valores e de suas lembranças, faz entrar em crise sua relação com a linguagem (BARTHES, 1987, p. 20-21 - grifos do autor).
\end{abstract}

Os três textos, ao explorar o trânsito entre Eros e Thanatos, os gêmeos complementares e opostos, são esses textos que de certo modo, podem colocar leitores e leitoras em crise, caso muito apegados com certa ideia da escrita do erotismo por mulheres. Textos que até podem ser sobre o prazer, mas não são textos de prazer, no sentido barthesiano, pois tornam complexas as relações dos sujeitos retratados com seu corpo e com a consequente finitude provável ou inadiável da carne perecível. A relação sexual é então, esse momento em que duas existências se reúnem, com seus dramas, sufocamentos e obsessões para, de algum modo escapar à descontinuidade pelo êxtase, ainda que no paroxismo de sua dissolução total.

O estudo das antologias nos reenvia, por fim, ao estudo de Antonio Candido sobre o direito à literatura. Lendo as proposições do texto de Candido a contrapelo, poderíamos fazer o exercício de pensar o lugar da literatura erótica nesse direito. Inicialmente, é preciso garantir o direito das escritoras se expressarem sobre temáticas sexuais sem que isso resulte em julgamentos morais e ataques à sua identidade de escritora, como já reivindicava Clarice Lispector em seu $A$ via crucis do corpo, nos idos anos 
1970. Garantir que não sejam julgadas obscenas, como também reivindicaria Marcia Denser ou Hilda Hilst décadas depois. O direito ao erótico e sua expressão, à criação de imagens e enunciados, o direito a escrever o gozo, seja ele o gozo da morte ou da vida, deve ser dado a qualquer indivíduo adulto, independente do gênero.

Para usar a terminologia de Elódia Xavier (2007), em vez de corpos apenas erotizados, pressupondo certa passividade, constituir corpos efetivamente liberados, plenos de autonomia tanto para o sexo, quanto para a escrita de seus temas. Garantir às mulheres o gozo da escrita erótica e o gozo da leitura tida sempre como proibida parece ainda ser um desafio quando nos debruçamos sobre o conjunto considerável de textos que compõem as antologias e que, não raras vezes, são ilustres desconhecidos da maioria dos leitores e leitoras, precisando ser "resgatados", incansavelmente, por quem se disponha a fazê-lo.

\section{Referências}

ANAïS, N. Delta de Vênus: histórias eróticas. Porto Alegre: L\&PM, 2005.

ANDREAS-SALOMÉ, L. (1910). El erotismo. Palma: Hesperus, 2014.

BARTHES, R. O prazer do texto. São Paulo: Perspectiva, 1987.

BATAILLE, G. O erotismo. São Paulo: Arx, 2004.

BORGES, L. O erotismo como ruptura na ficção brasileira de autoria feminina: um estudo de Clarice Lispector, Hilda Hilst e Fernanda Young. Florianópolis: Editora Mulheres, 2013.

BUTLER, J. Problemas de gênero: feminismo e subversão da identidade. Rio de Janeiro: Civilização Brasileira, 2003.

CANDIDO, A. O direito à literatura. In: Vários escritos. São Paulo: Duas Cidades, 1995. p. 235-263

FOUCAULT, M. História da sexualidade I: a vontade de saber. Rio de Janeiro: Edições Graal, 2001.

GRAMMONT, G. de. S. In: COELHO, L. (Org.). Intimidades: dez contos eróticos de escritoras brasileiras e portuguesa. Rio de Janeiro: Record: 2005. p. 45-54.

HISGAIL, F. A construção erótica segundo Lou Andreas-Salomé. Redoma Crítica, nov. 2017.2 Disponível em: 
http://redomacritica.blogspot.com/2017/11/a-construcao-erotica-segundolou.html. Acesso em 11 de julho de 2019.

LEMAIRE, Repensando a história literária. In: HOLLANDA, H. B. de. Tendências e impasses: o feminismo como crítica da cultura. Rio de Janeiro: Rocco, 1994. p. 58-71.

MIRANDA, A. Animal. In: COELHO, L. (Org.). Intimidades: dez contos eróticos de escritoras brasileiras e portuguesa. Rio de Janeiro: Record: 2005. p. 31-34

PEDROSA, I. Só sexo. In: COELHO, L. (Org.). Intimidades: dez contos eróticos de escritoras brasileiras e portuguesa. Rio de Janeiro: Record: 2005. p. 55-66.

XAVIER, E. Que corpo é esse? O corpo no imaginário feminino. Florianópolis: Editora Mulheres, 2007. 